\title{
Construction and Biological Performance of Porous Titanium Surface Nanotube Arrays
}

\section{Xingping Fan}

Panzhihua University, Panzhihua, Sichuan, PR China

\begin{abstract}
$\mathrm{TiO}_{2}$ nanotube array films were prepared on porous titanium via anodic oxidation. The morphology and phases of the films were characterized, and the thermal stability, bioactivity in-vitro, biocompatibility in vivo, and osteoinductivity of the films were also studied. It was found the anatase nanotubues give better bioactivity than the amorphous. The porous titanium after anodic oxidation and annealing at $500{ }^{\circ} \mathrm{C}$ formed hydroxyapatite on surface and can induce blood vessel formation and promote the expressions of bone morphogenetic protein BMP-2, which contribute to the potential osteoinductivity. This study will promote the development of novel functional porous supports.
\end{abstract}

\section{Keywords}

Porous, Anodic oxidation, Nanotubue array, Bioactivity, Osteoinductivity

\section{Introduction}

As is well-known, titanium (Ti) and its alloys are often used in biomaterials because of high strength, toughness and corrosion resistance [14]. However, such alloy tissues have far larger elastic modulus than human bones, which can easily cause stress shield and bone absorption. The high-porosity porous titanium can match with bone tissues in terms of mechanical properties, and the penetrated hole structures can even offer larger space for tissue growth, offering channels for body liquid flow and nutrition exchange, which are favorable for the inward growth of surrounding cells and new bone growth and strengthen the bio-fixation of bone tissues [5]. However, the Ti surfaces can be easily oxidized into a layer of dense oxidation films, which increase the biological inertia of Ti. The binding between $\mathrm{Ti}$ and bones belongs to mechanical inter-locking. Recently, surface modification of metal Ti and its alloys becomes one of the research hotspots in the field of biomedical materials. Surface modification endows Ti and its alloys with bioactivity, so that the new bones can directly bind with the implant surfaces without needing any connective tissues, which directly contributes to osseointegration or bone bonding.

At present, there are many compact Ti surface modification methods, including plasma spraying [6], ion implantation [7], magnetron sputtering [8], acid treatment [9], electrochemical deposition [10], anodic oxidation, and microarc oxidation process [11-13]. However, there is little research about porous titanium modification. Owing to the three-di-

*Corresponding author: Xingping Fan, Panzhihua University, Panzhihua, Sichuan, PR China

Accepted: January 30, 2020; Published: February 01, 2020

Copyright: (c) 2020 Fan X. This is an open-access article distributed under the terms of the Creative Commons Attribution License, which permits unrestricted use, distribution, and reproduction in any medium, provided the original author and source are credited.

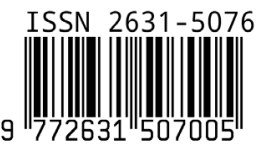

Fan. Int J Metall Met Phys 2020, 5:043 
mensional structures of porous titanium, the commonly used physical modification methods are ineffective for the internal parts of pores. Due to the three-dimensional structures of porous titanium, the commonly used physical modification methods are ineffective for the internal parts of pores. Thus, appropriate methods are needed to modify porous titanium. Ti with micronano structures or after alkali treatment can induce apatite formation and efficiently promote cell adhesion, growth and differentiation $[14,15]$.

Bone repair materials should also possess suitable osteoinductivity in addition to the mechanical properties and excellent osteoconductivity that match with bones. Once osteoinductivity is possessed, the formation of new bone tissues can be induced during bone repair, and the bone repair time can be shortened, which effectively improve the bone repair effect. So far, the well-known osteoinductive material is hydroxyapatite. Other osteoinductive materials have been rarely reported. Fujibayashi, et al. found osteoinductivity of the porous titanium suppressed from titanium wire can be induced after 12 months of implantation into animals in vivo [16].

At present, there is much research about the surface nanocrystallization of dense titanium and its alloys, but the surface anodic oxidation nanocrystallization of porous titanium has been rarely reported, especially the effects of surface nanocrystallization on the biocompatibility of porous titanium plates. For this reason, we surface-modified porous titanium with the anodic oxidation process and thereby prepared a nanotube array, which was then thermally treated at different temperatures. The morphology and phases of the $\mathrm{TiO}_{2}$ nanotube array were observed, and its bioactivity and biocompatibility were investigated via in-vitro bionic mineralization experiments and animal in-vivo implantation experiments respectively. Also, its feasibility into the field of biomaterials was explored.

\section{Materials and Methods}

\section{Preparation and surface nanotube morpholo- gy of porous titanium}

The commercial pure 300-mesh titanium powder was used here, and $\mathrm{NH}_{4} \mathrm{HCO}_{3}$ (granularity 100-300 $\mu \mathrm{m}$ ) was adopted as the pore-forming agent. The titanium powder and $\mathrm{NH}_{4} \mathrm{HCO}_{3}$ were mixed evenly at the mass fraction ratio of $1: 1$ under even stirring and then placed into a mold, in which a miniature hydraulic press pressed the mixture into specimens at the pressure of 80 $\mathrm{MPa}$. The molded specimens were preserved in a common muffle furnace at $100^{\circ} \mathrm{C}$ for $5 \mathrm{~h}$ in order to completely remove the pore-forming agent, then heated to $1300{ }^{\circ} \mathrm{C}$ in a vacuum furnace, and heat-preserved for $2 \mathrm{~h}$. (Figure 1 ) shows the process flow diagram about the preparation of high-porosity porous titanium [17].

The sintered porous Ti sheets ( $\left.\Phi 5 \times \mathrm{L} 3 \mathrm{~mm}^{2}\right)$ were ultrasonically washed with ethanol and deionized water and then dried. The specimens were processed via anodic oxidation in the mode of constant-voltage direct-current continuous feeding, in which the anode was porous titanium, the cathode was graphite, and the electrolyte was a mixture of $0.15 \mathrm{~mol} / \mathrm{L}$ fluohydric acid and $0.1 \mathrm{~mol} / \mathrm{L}$ nitric acid. After $60 \mathrm{~min}$ of oxida-

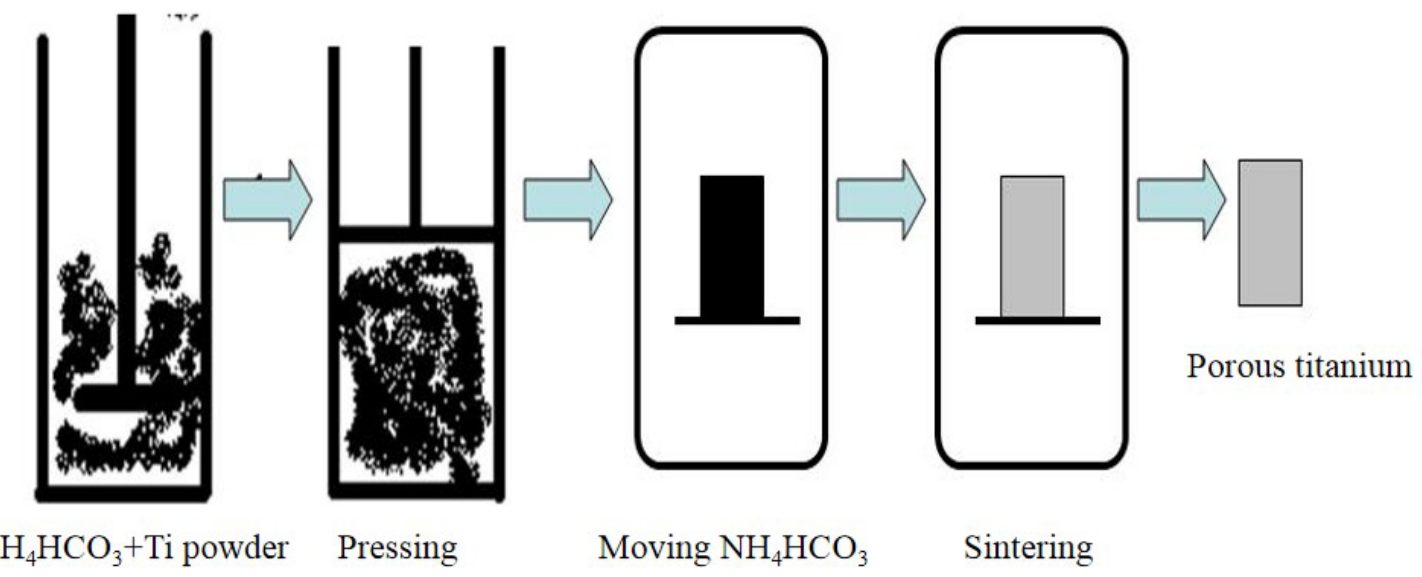

Figure 1: Preparation process of porous titanium with high porosity. 
Table 1: Order, amounts and purities for preparing 1000 $\mathrm{ml}$ of SBF.

\begin{tabular}{|l|l|l|l|}
\hline Order & Reagent & Amount & Purity (\%) \\
\hline $\mathbf{1}$ & $\mathrm{NaCl}$ & $8.035 \mathrm{~g}$ & 99.5 \\
\hline $\mathbf{2}$ & $\mathrm{NaHCO}$ & $0.355 \mathrm{~g}$ & 99.5 \\
\hline $\mathbf{3}$ & $\mathrm{KCl}$ & $0.225 \mathrm{~g}$ & 99.5 \\
\hline $\mathbf{4}$ & $\mathrm{K}_{2} \mathrm{HPO}_{4} \cdot 3 \mathrm{H}_{2} \mathrm{O}$ & $0.231 \mathrm{~g}$ & 99.0 \\
\hline $\mathbf{5}$ & $\mathrm{MgCl}_{2} \cdot 6 \mathrm{H}_{2} \mathrm{O}$ & $0.311 \mathrm{~g}$ & 99.0 \\
\hline $\mathbf{6}$ & $1.0 \mathrm{M} \mathrm{HCl}^{\mathrm{H}}$ & $39 \mathrm{ml}$ & - \\
\hline $\mathbf{7}$ & $\mathrm{CaCl}_{2}$ & $0.292 \mathrm{~g}$ & 95.0 \\
\hline $\mathbf{8}$ & $\mathrm{Na}_{2} \mathrm{SO}_{4}$ & $0.072 \mathrm{~g}$ & 99.0 \\
\hline $\mathbf{9}$ & $\mathrm{CNH}_{2}\left(\mathrm{CH}_{2} \mathrm{OH}\right)_{3}$ & $6.118 \mathrm{~g}$ & 99.0 \\
\hline $\mathbf{1 0}$ & $1.0 \mathrm{M} \mathrm{HCl}$ & $0.5 \mathrm{ml}$ & - \\
\hline
\end{tabular}

tion at the voltage of $20 \mathrm{~V}$, the specimens were taken out, washed with distilled water and dried.

Three groups were set: (1) Untreated porous titanium (UPT); (2) Anodically oxidated porous titanium at $20 \mathrm{~V}$ for $1 \mathrm{~h}$ (APT); (3) Anodically oxidated $(1 \mathrm{~h}$ of at $20 \mathrm{~V})$ and heat-preserved $\left(5 \mathrm{~h}\right.$ at $\left.500^{\circ} \mathrm{C}\right)$ porous titanium (HAPT).

\section{In-vitro mineralization experiments}

A simulated body fluid (SBF) was prepared according to the composition by Tadashi Kokubo [18], and the composition and preparation order were shown in Table 1.

The specimens after the above microarc oxidation were soaked in the SBF at $37{ }^{\circ} \mathrm{C}$. The SBF was changed once every day. The composition and preparation order of SBF were shown in Table 1. According to the preparation order, the substances were successively dissolved in deionized water and particularly, $\mathrm{CaCl}_{2}$ was dissolved slowly in order to avoid precipitation. The Tris $\left[\mathrm{H}_{2} \mathrm{NC}\left(\mathrm{CH}_{2} \mathrm{OH}\right)_{3}\right]$ and $\mathrm{HCl}$ were alternatively dripped to maintain the $\mathrm{pH}$ around 7 , and finally, after Tris was all dripped, the $\mathrm{pH}$ was controlled at 7.40 by dripping $\mathrm{HCl}$. After 7 days, the specimens were taken out, rinsed with deionized water and air-dried.

\section{Animal in-vivo implantation experiments}

Sample preparation: The porous titanium with porosity of $70 \%$ was prepared by adding a pore-forming agent, and the porosity measurement method can be found in literature. The

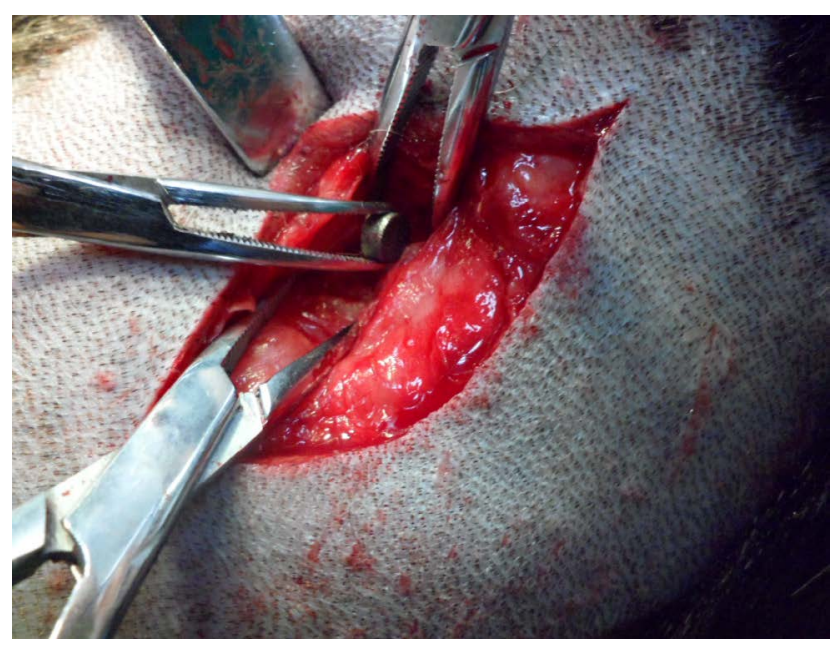

Figure 2: Implants embedded in muscle of dog.

specimens were in size of $\Phi 5 \times \mathrm{L} 3 \mathrm{~mm}^{2}$, and each group involved 2 specimens. The implanted specimens were classified into groups UPT, APT and HAPT.

Operation: Healthy adult dogs (16-20 kg) were used to build an animal model. The implantation site was the back muscles. Each dog was intraperitoneally anesthetized with $1 \mathrm{~mL} / \mathrm{kg}$ of $3 \%$ pentobarbital sodium, and the back was unhaired, followed by iodine alcohol disinfection and draping. The muscle tissues were dissected, and the 3 groups of UPT, APT and HAPT were sterilized and randomly implanted into muscles (Figure 2). The cuts were sutured. The muscles were injected with penicillin to prevent infection for one week postoperatively.

Detection methods: Postoperatively, the dogs were generally observed, including the feeding and the inflammation at injured sites. At 6 months postoperatively, the dogs were injected with excessive anesthetics, sacrificed, and the occurrence of purulency, inflaming or necrosis between the surrounding tissues and the implanted material was observed.

As for histomorphologic observation, the specimens were fixed one-time, penetrated, embedded, but into hard tissues, coated and stained.

The specimens were analyzed by a bone morphogenetic protein-2 (BMP-2) enzyme-linked immunosorbent assay (ELISA) kit (Canine Bone Morphogenetic Protein 2).

\section{Statistical analysis}

The results of BMP-2 concentrations were sta- 
tistically analyzed via one-way analysis of variance (ANOVA) (Student-Newman-Keuls) at the significance level of $p<0.05$.

\section{Results and Discussion}

\section{Porous titanium mesh 3D support and surface nanotube morphology observation}

To investigate how subsequent treatment affected the performances of porous titanium, we designed three groups: (1) Untreated porous titanium (UPT); (2) Anodically oxidated porous ti- tanium for $1 \mathrm{~h}$ at $20 \mathrm{~V}$ (APT); (3) Anodically oxidated ( $1 \mathrm{~h}$ at $20 \mathrm{~V}$ ) and heat-preserved ( $5 \mathrm{~h}$ at 500 ${ }^{\circ} \mathrm{C}$ ) porous titanium (HAPT). (Figure 3 ) shows the surface morphology of different specimens. Results showed the number of surface micropores increased after the anodic oxidation (Figure 3c). Moreover, the high-resolution images showed the microcosmic surface of UPT was even (Figure $3 d$ ). After the anodic oxidation, nanotubes in diameter of $\sim 100 \mathrm{~nm}$ were formed on surface (Figure 3e). The tube morphology after thermal treatment was nearly unchanged (Figure $3 \mathrm{f}$ ).
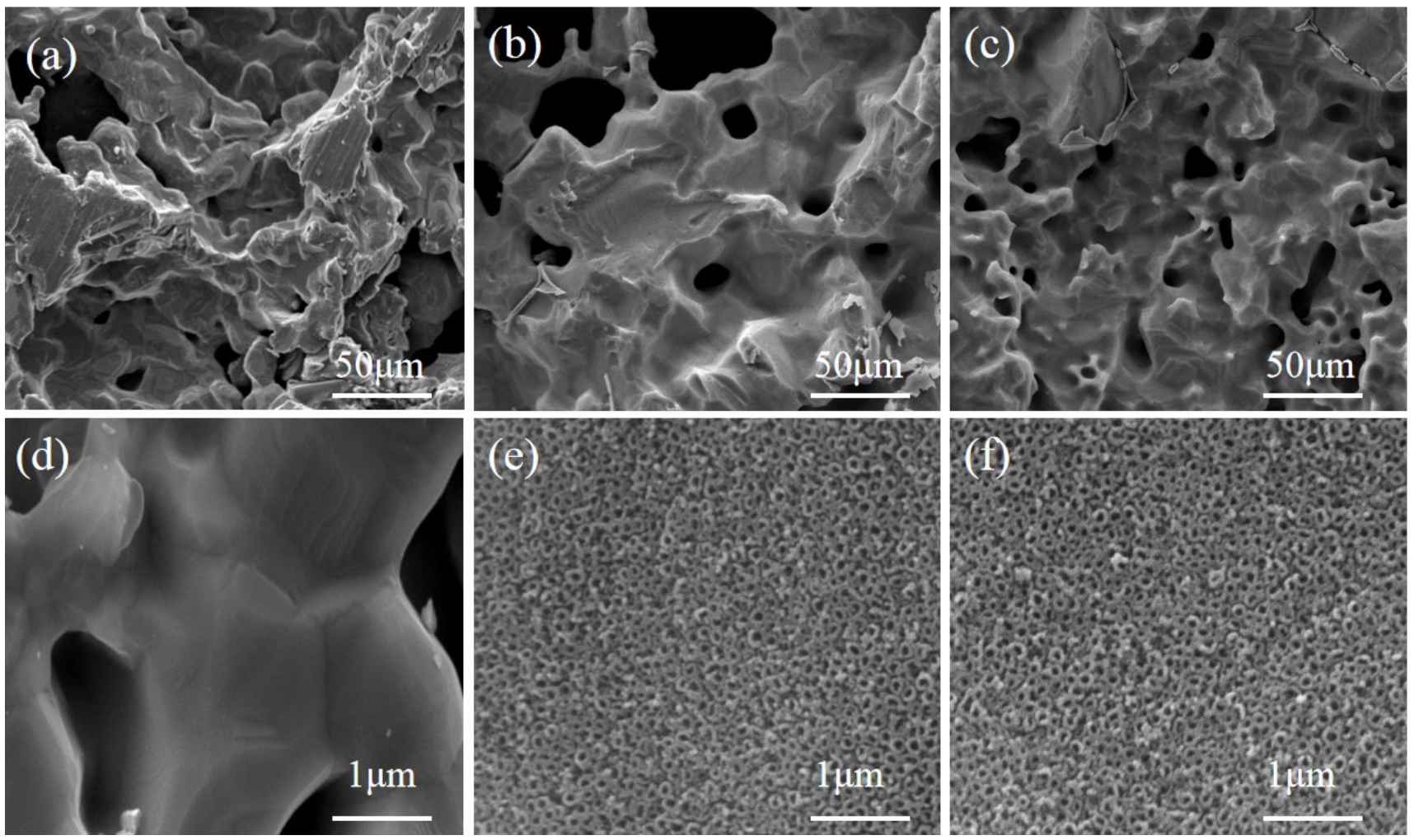

Figure 3: Morphology of specimens after different treatments: $a, b$ and d): Morphology after UPT at different resolutions; c and e): Low-resolution and high-resolution morphology after APT; f): Morphology after HAPT.
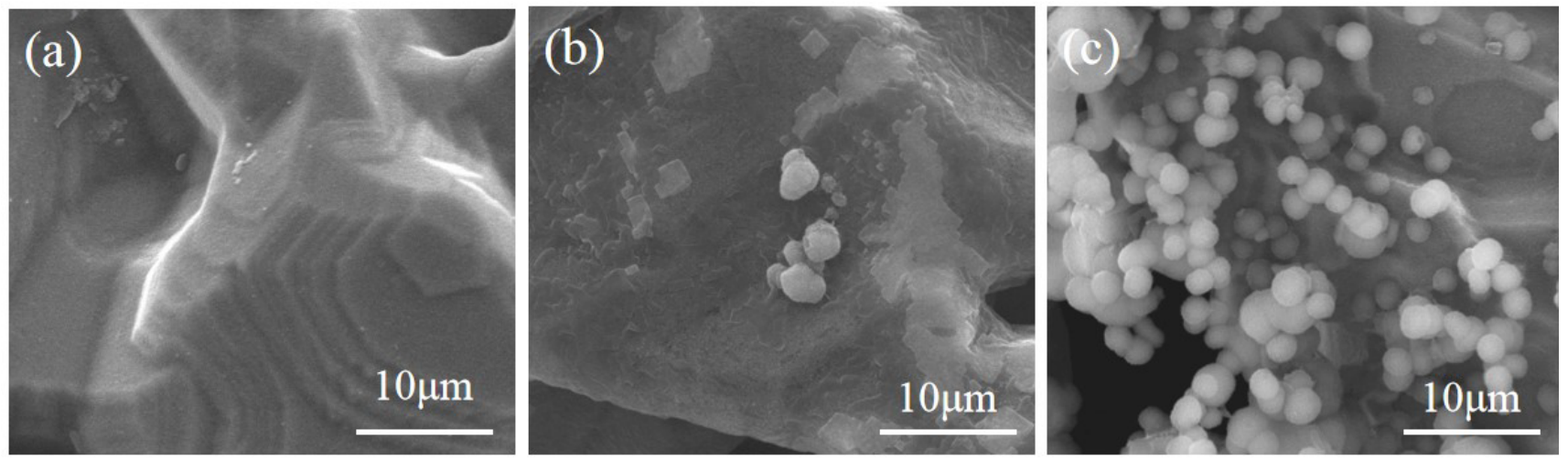

Figure 4: Morphology after immersion in SBF for 7 days: a) UPT, b) APT and c) HAPT. 
Analysis showed nanotubes of porous titanium cannot be formed at too high or too low voltage, since regularly arranged nanotubes were generated only after oxidation at the voltage of $25 \mathrm{~V}$ and were still well reserved after thermal treatment. In this way, micronano structured porous titanium was generated.

\section{In-vitro bioactivity evaluation}

Figure 4 shows the morphology of porous titanium after bionic mineralization. After 7 days of immersion in $2 \mathrm{SBF}$, no surface precipitate was formed in the UPT and the morphology after immersion was unchanged (Figure 4a). In the APT, the specimens containing surface nanotubes were found with minor spherical substances and were locally covered by white matter (Figure 4b). After the HAPT was mineralized, dense pellets

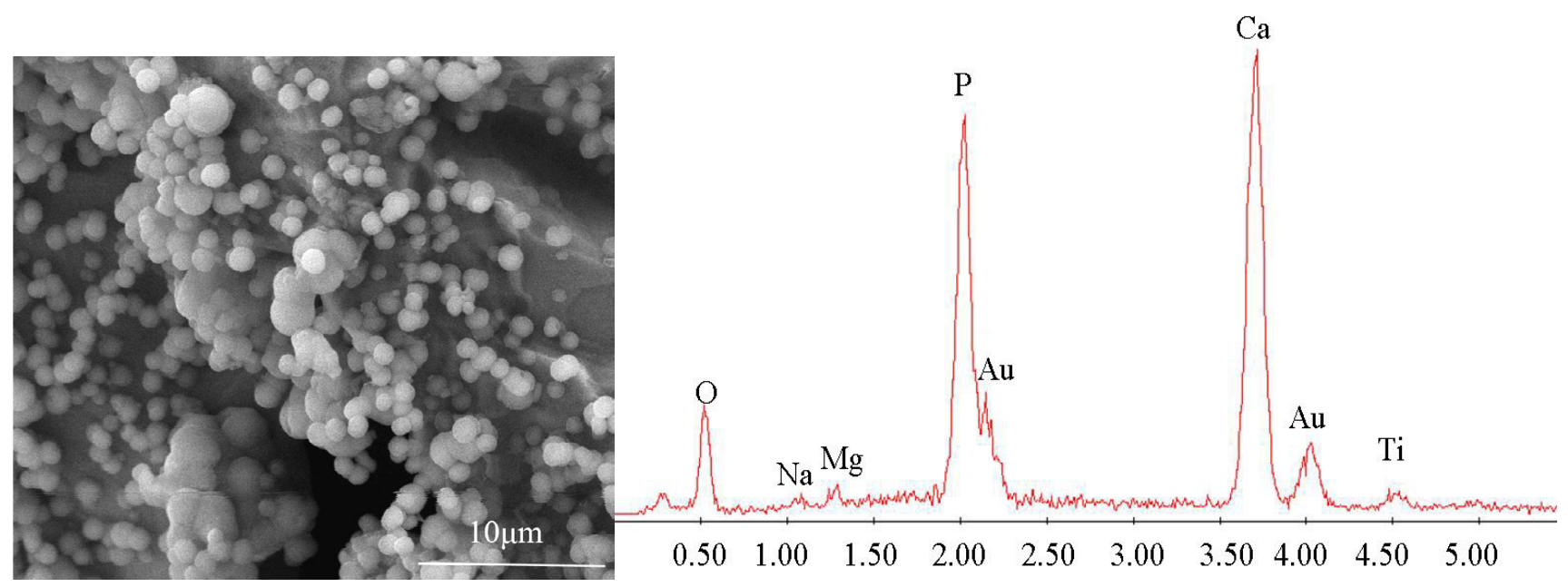

Figure 5: SEM and EDS images of HAPT after 7 days of mineralization.

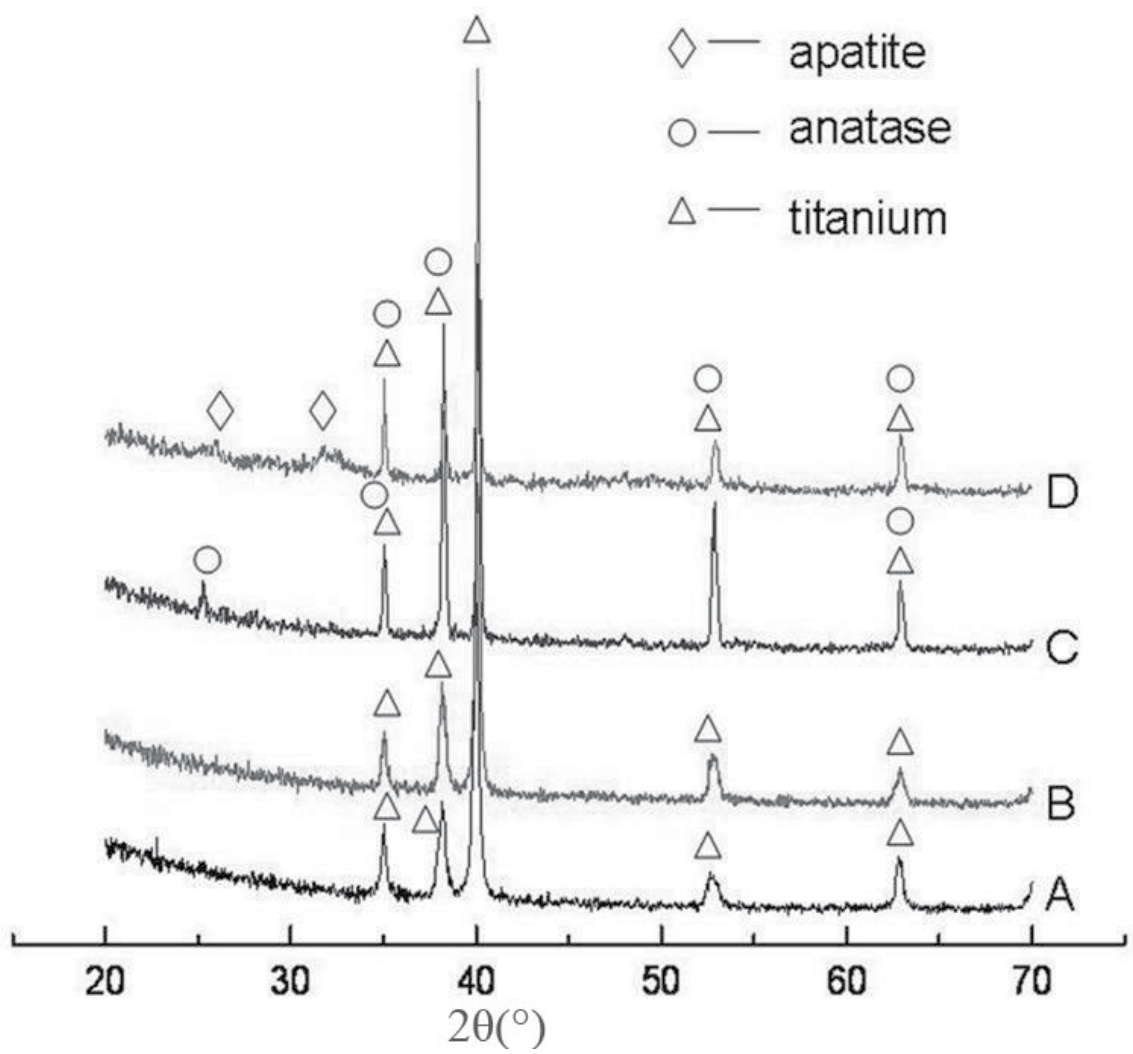

Figure 6: XRD patterns of different specimens: A: UPT; B: APT; C: HAPT; D: HAPT after 7 days of immersion in 2SBF. 
were formed on surface (Figure 4c). EDS showed these pellets were mainly composed of $\mathrm{Ca}, \mathrm{P}$ and $\mathrm{O}$ (Figure 5).

Figure 6 shows the corresponding XRD patterns, in which (a) and (b) are UPT and APT respectively. Together with Figure 3 , it is clear the surface nanotubes after anodic oxidation are amorphous $\mathrm{Ti}-\mathrm{O}$ compounds. Anatase was formed after thermal treatment at $500{ }^{\circ} \mathrm{C}$ (Figure $6)$. The thermal treatment promoted the formation of apatite (Figure $6 \mathrm{~d}$ ).

The effects of $\mathrm{TiO}_{2}$ crystal form on apatite precipitation induction have been studied. Shi, et al. investigated how the brookite, anatase and rutile after thermal treatment at different temperatures affected hydroxyapatite formation and found the anatase-phase and brookite-phase $\mathrm{TiO}_{2}$ were the most and least effective in inducing hydroxyapatite precipitation respectively [19], but the reasons were not analyzed. Zhao, et al. found crystal forms significantly affected the bioactivity of $\mathrm{TiO}_{2}$ films and both anatase and rutile $\mathrm{TiO}_{2}$ films can well induce apatite formation [20]. Lin, et al. found the structural matching between anatase and apatite largely induced apatite generation, and the (100) plane of anatase was in parallel to the (100) plane of apatite, and the [001] and [010] orientations of anatase were parallel to the [010] and [001] orientations of apatite respectively [20]. Moreover, the distance between $O$ atoms at the [010] and [010] orientations on the (100) plane of anatase was 0.95 and $0.378 \mathrm{~nm}$ respectively; the distance between hydroxyl groups at the [010] and [001] orientations on the (100) plane of apatite was 0.942 and
$0.687 \mathrm{~nm}$ respectively [21]. Hydroxyapatite can preferentially grow along the $<001>$ orientation family on the (001) plane of rutile [22]. Our study also showed the anatase $\mathrm{TiO}_{2}$ nanotubes on the porous titanium substrate was more able than the amorphous $\mathrm{TiO}_{2}$ nanotubes to induce apatite formation, which may be attributed to the phase structure matching between anatase and apatite.

\section{Osteoinductivity}

General observation by naked eyes: After the operations, the dogs ate and behaved normally, and no inflammation or infection occurred on the injuries at the implantation sites. During the sampling, the materials were surrounded by tissues, and no purulency or tissue necrosis was found around the materials.

Histological observation: Figure 7 shows the histological images at 6 months after implantation of porous titanium into dog back muscles. Clearly, tissue growth occurred at all implanted bodies, but no new bones were formed, and new tubes were found only in the HAPT group (arrowhead in Figure $7 c$ ). Connective tissues were formed in all other pores (Figure 7a and Figure 7b).

BMP-2 ELISA: Figure 8 shows the BMP-2 concentrations in different specimens. Clearly, at 6 months after implantation into muscles, BMP-2 was detected in all specimens, and the average concentration minimized to $2.78 \pm 0.16 \mu \mathrm{g} / \mathrm{L}$ in the UPT group. The BMP-2 concentrations in the APT group slightly increased to $2.86 \pm 0.17 \mu \mathrm{g} / \mathrm{L}$, but was not significantly different from the UPT group. The BMP-2 concentrations in the HAPT
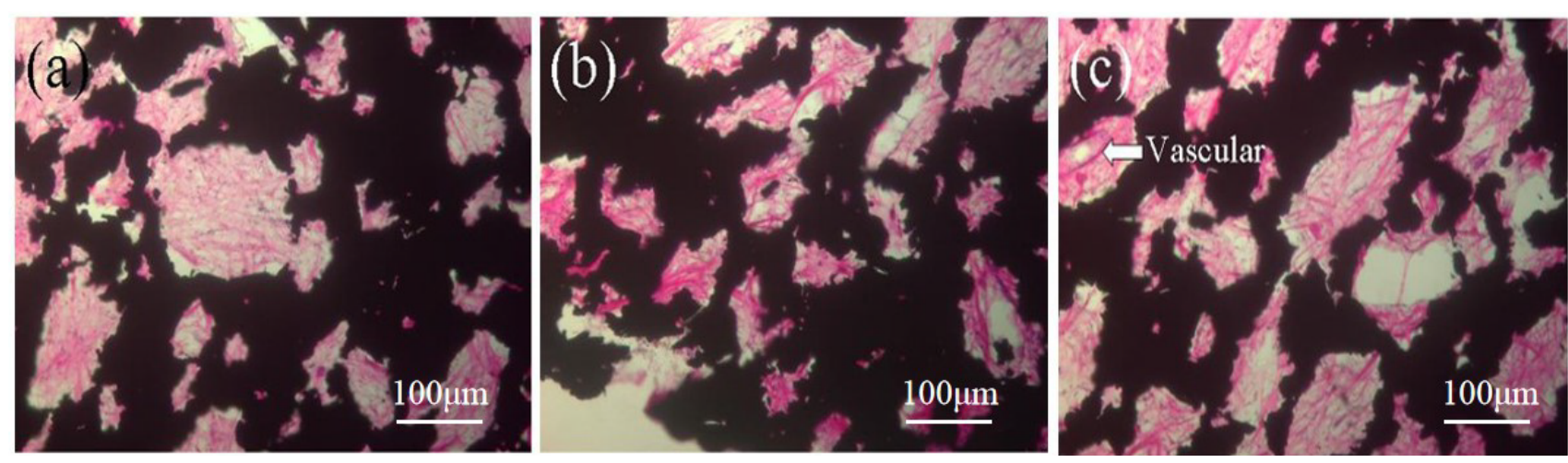

Figure 7: Histological stained images at 6 months after implantation of porous titanium into dog back muscles (hematoxylin-eosin staining): a) UPT; b) APT; c) HAPT. 


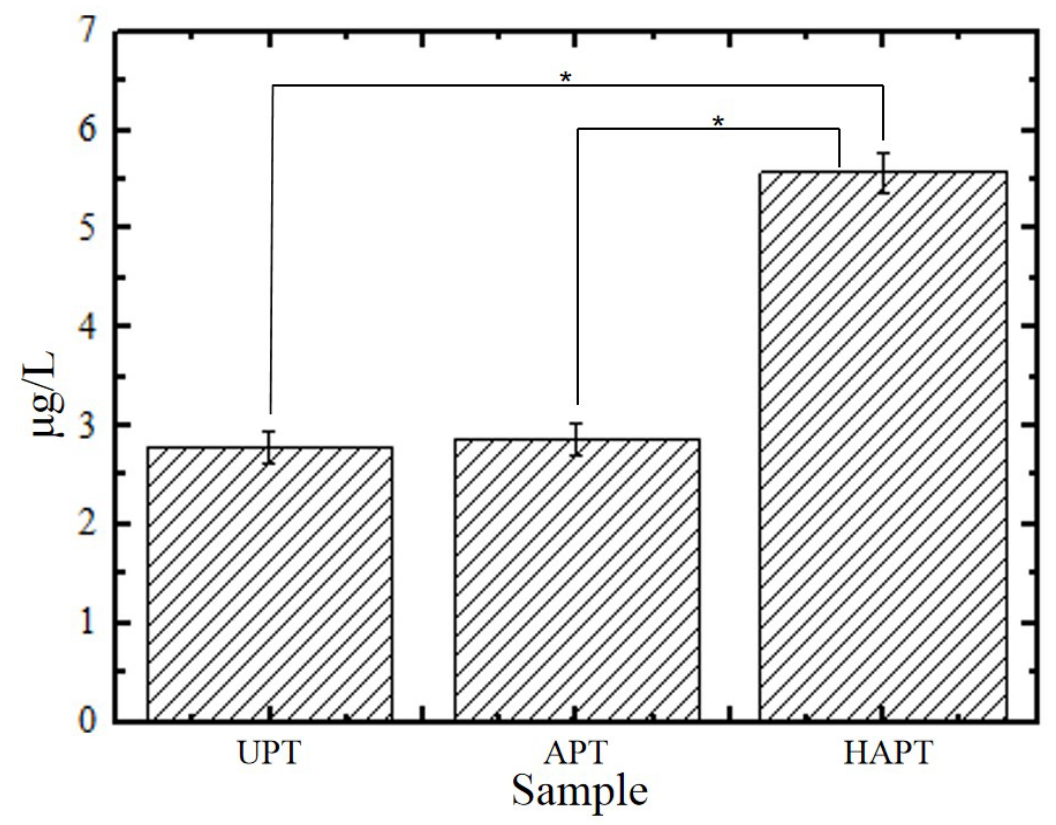

Figure 8: BMP-2 concentrations at 6 months after muscle implantation $\left({ }^{*}: p<0.05\right)$.

group significantly increased to $5.57 \pm 0.20 \mu \mathrm{g} / \mathrm{L}$ compared with the other two groups, indicating the thermal treatment following oxidation can considerably upregulate BMP-2 expression.

It was once believed that the osteoinductivity of biomaterials cannot be achieved with the absence of BMP and other bone growth factors. However, recent research showed some calcium phosphate biomaterials with special pore structures were osteoinductive [23-25]. Metallic titanium was often considered as a biological inert material, and the titanium used as scaffold materials can promote bone formation through BMPs or induce heterotopic ossification through cell implantation [26]. The main biological functions of BMPs are to induce the differentiation of undifferentiated mesenchymal cells into cartilage and bones [27]. Thus, BMPs can considerably promote bone formation during bone repair. Nevertheless, the mechanism of osteoinductivity is very complex and unknown so far. Fujibayashi, et al. generally analyzed the causes of $\mathrm{Ca}$ - and $\mathrm{P}$-containing biomaterials and pointed to the association with surface composition and surface morphology [16]. In-depth research showed osteoinductivity was closely related to the microstructures of materials in addition to material composition, and surface composition and microstructure both contributed to the enrichment of BMPs $[23,28-30]$. Moreover, the thickness, po- rosity, pore size distribution and crystal forms of the implanted oxides all affected the bone tissue reactions [31], but it was unclear whether these factors acted alone or jointly [32].

Our results can also be interpreted by the above reasons. The BMP-2 expression of the APT group was slightly higher than in the UPT group, which may be attributed to the effect of surface nanostructures. Though no new bone formation was found directly, new blood vessels were formed in the HAPT group, and the new vessels or peripheral tissues can offer the mesenchymal cells for osteoinductivity. Moreover, the BMP-2 concentration in the HAPT group was significantly higher than in the other two groups, indicating the HAPT treatment can upregulate BMP-2 expression. The possible reason is that the surface anatase $\mathrm{TiO}_{2}$ nanotubes in the HAPT group and the unique crystal forms excited the BMP-2 expression and thereby promoted new bone formation. The above analysis suggests microstructures and crystal form can affect osteoinductivity, and the nanostructured $\mathrm{TiO}_{2}$ crystal form is probably more contributive to osteoinductivity. Moreover, osteoinductivity may also be related to the micropore structures of porous titanium. Fukuda, et al. investigated how the edge length of squared open pores $(500,600,700,800,900$, or $1200 \mu \mathrm{m}$ ) affected osteoinductivity and implanted the specimens after alkali thermal treat- 
ment to dog back muscles and found the osteoinductivity was higher at the edge length of 500 and $600 \mu \mathrm{m}$, indicating osteoinductivity is associated with pore size [33]. Zhang, et al. studied the osteoinductivity of calcium phosphate and found the macropores at hundreds of micrometer and the inner wall microscale micropores were important reasons for the osteoinductivity [28-30]. In our study, the porous titanium after anodic oxidation and thermal treatment was found with both macropores at hundreds of micrometer and nanoscale or microscale micropores, which may be one of the reasons for the osteoinductivity.

\section{Conclusions}

In-vitro bionic mineralization experiments showed the microstructured anatase porous titanium formed after anodic oxidation and thermal treatment was more able to induce hydroxyapatite formation. In-vivo experiments showed the porous titanium was highly biocompatible in the muscles. Though no new bones were directly found at 6 months after the implantation, the microstructured anatase porous titanium formed after anodic oxidation and thermal treatment induced blood vessel growth and promoted BMP-2 expression, which indicated the potential osteoinductivity.

\section{References}

1. M Geetha, AK Singh, R Asokamani, AK Gogia (2009) Ti based biomaterials, the ultimate choice for orthopaedic implants-A review. Prog Mater Sci 54: $397-$ 425.

2. M Long, HJ Rack (1998) Titanium alloys in total joint replacement-A materials science perspective. Biomaterials 19: 1621-1639.

3. D Kuroda, M Niinomi, M Morinaga, Y Kato, T Yashiro (1998) Design and mechanical properties of new $\beta$ type titanium alloys for implant materials. Mater Sci Eng A 243: 244-249.

4. M Niinomi (2003) Recent research and development in titanium alloys for biomedical applications and healthcare goods. Sci Technol Adv Mater 4: 445-454.

5. CE Wen, M Mabuchi, Y Yamada, K Shimojima, Y Chino, et al. (2001) Processing of biocompatible porous Ti and Mg. Scripta Mater 45: 1147-1153.

6. A Cunha, RP Renz, E Blando, RB Oliveira, R Hübler (2014) Osseointegration of atmospheric plasma-sprayed titanium implants: Influence of the native oxide layer. J Biomed Mater Res A 102: 30-36.
7. HL Cao, XY Liu, FH Meng, PK Chub (2011) Biological actions of silver nanoparticles embedded in titanium controlled by micro-galvanic effects. Biomaterials 32: 693-705.

8. LX Xu, YX Leng, HF Zhou, YW Liu, N Huang (2005) Structure and hemocompatibility of titanium oxide films synthesized by continuous or pulsed DC magnetron sputtering. Key Eng Mater 288-289: 299-302.

9. H Xu, W Yan, L You (2011) Effects of various acids treatment on the properties of titanium substrate. Rare Metal Mat Eng 40: 1550-1554.

10.M Wei, AJ Ruys, MV Swain, SH Kim, BK Milthorpe, et al. (1999) Interfacial bond strength of electrophoretically deposited hydroxyapatite coatings on metals. J Mater Sci Mater Med 10: 401-409.

11.K Lee, A Mazare, P Schmuki (2014) One-dimensional titanium dioxide nanomaterials: Nanotubes. Chem Rev 114: 9385-9454.

12.Q Du, DQ Wei, YM Wang, S Cheng, S Liu, et al. (2018) The effect of applied voltages on the structure, apatite-inducing ability and antibacterial ability of micro arc oxidation coating formed on titanium surface. Bioact Mater 3: 426-433.

13.YD Li, WQ Wang, HY Liu, JW Lei, JY Zhang, et al. (2018) Formation and in vitro/in vivo performance of "cortex-like" micro/nano-structured TiO2 coatings on titanium by micro-arc oxidation. Mater Sci Eng $C$ 87: 90-103.

14.J Kunze, L Müller, JM Macak, P Greil, P Schmuki, et al. (2008) Time-dependent growth of biomimetic apatite on anodic $\mathrm{TiO} 2$ nanotubes. Electrochim Acta 53: 6995-7003.

15.K Anselme, P Davidson, AM Popa, M Giazzon, M Liley, et al. (2010) The interaction of cells and bacteria with surfaces structured at the nanometer scale. Acta Biomaterialia 6: 3824-3846.

16.S Fujibayashi, M Neo, HM Kim, T Kokubo, T Nakamura (2004) Osteoinduction of porous bioactive titanium metal. Biomaterials 25: 443-450.

17.XP Fan (2014) Preparation of porous titanium with high porosity and surface modification by micro-arc oxidation. Heat Treat Met 39: 50-53.

18. Kokubo T, Takadama H (2006) How useful is SBF in prediction in vivo bone bioactivity? Biomaterials 27: 2907-2915.

19.P Shi, Q Yu (2010) Inducing effects of annealing temperature and $\mathrm{TiO} 2$ structure on deposition of hydroxyapatite. T Mater Heat Treat 31: 44-47.

20.XB Zhao, J You, L Ma, ZG Chen (2010) Effect of 
phase composition on bioactivities of titania films. B Chin Ceram Soc 38: 148-152.

21.CM Lin, SK Yen (2006) Biomimetic growth of apatite on electrolytic $\mathrm{TiO} 2$ coatings in simulated body fliud. Mater Sci Eng C 26: 54-65.

22.F Lindberg, J Heinrichs, F Ericson, P Thomsen (2008) Hydroxyapatite growth on single-crystal tutile substrates. Biomaterials 29: 3317-3323.

23. HP Yuan, YB Li, JD Bruijn, KD Groot, XD Zhang (2000) Tissue responses of calcium phosphate cement: $A$ study in dogs. Biomaterials 21: 1283-1290.

24.ZJ Yang, HP Yuan, WD Tong, P Zou, WQ Chen, et al. (1996) Osteogenesis in eztrakseletally implanted porous calcium phosphate ceramics: Variability among different kinds of animals. Biomaterials 17: 21312137.

25.U Ripamonti (1996) Osteoinduction in porous hydroxyapatite implanted in heterotopic sites of different animal models. Biomaterials 17: 31-35.

26.JWM Vohof, PHM Spauwen, JA Jansen (2000) Bone formation in calcium-phosphate-coated titanium mesh. Biomaterials 21: 2003-2009.

27.JQ Xu, YY Hu, F Xu, K Lian, R Lv, et al. (2002) An experiment research of the composite of rhBMP-2 and Lecithin in repairing the segmental defect of dog's long bone. Orthop J Chin 9: 593-595.
28. HP Yuan, ZJ Yang, JD Bruijn, K de Groot, XD Zhang (2001) Material-dependent bone induction by calcium phosphate ceramics: A 2.5 -year study in dog. Biomaterials 22: 2617-2623.

29.SX Qu, X Guo, J Weng, JCY Cheng, B Feng, et al. (2004) Evaluation of the expression of collagen type I in porous calcium phosphate ceramics implanted in an extra-osseous site. Biomaterials 25: 659-667.

30.HP Yuan, K Kurashina, JD de Bruijn, YB Li, K de Groot, et al. (1999) A preliminary study on osteoinduction of two kinds of calcium phosphate ceramics. Biomaterials 20: 1799-1806.

31.YT Sul, CB Johansson, Y Jeong, A Wennerberg, T Albrektsson (2002) Resonance frequency and removal torque anlysis of implants with turned and anodized surface oxides. Clin Oral Implants Res 13: 252-259.

32.YT Sul, CB Johansson, K Röser, T Albrektsson (2002) Qualitative and quantitative observations of bone tissue reactions to anodised implants. Biomaterials 23: $1809-1817$.

33.A Fukuda, M Takemoto, $T$ Saito, $S$ Fujibayashi, $M$ Neo, et al. (2011) Osteoinduction of porous Ti implants with a channel structure fabricated by selective laser melting. Acta Biomater 7: 2327-2336. 